\title{
Complication after implantation of a suprachoroidal Cyclosporine device in a horse a wandering implant
}

\author{
Hanneke Hermans and Jos M. Ensink \\ Department of Equine Sciences, Faculty of Veterinary Medicine, Utrecht University, Yalelaan 112, 3584 CM, Utrecht, the Netherlands
}

\begin{abstract}
Summary
A 19-year-old Dutch Warmblood mare was referred for the evaluation of acute corneal edema of the right eye. Ophthalmic examination revealed a vertical band of corneal edema and precipitates were visible on the endothelium. The pupil was miotic. Intraocular pressure was $15 \mathrm{~mm} \mathrm{Hg}$ compared to $19 \mathrm{~mm} \mathrm{Hg}$ in the left eye. Ultrasound examination showed no vitreal infiltrate or retinal detachment. A presumptive diagnosis of anterior uveitis was made. The horse reacted well to medical treatment with dexamethasone and atropine. Four weeks later the horse had a relapse of the clinical symptoms after discontinuation of the medication and a Cyclosporine $A$ (CsA) device was placed into the suprachoroidal space. The surgery was uneventful but postoperatively the horse had a severe recurrence of uveitis with blepharospasm, lacrimation, edema, a miotic pupil and an extensive web of fibrin in the anterior chamber. The horse reacted well to treatment. Approximately two months postoperatively, the CsA device was visible in the anterior chamber. The CsA device was not attached to the cornea. For three months the horse had no blepharospasm but had episodes of slight corneal edema. This usually cleared quickly on dexamethasone. Four months postoperatively, the horse had an episode with severe corneal edema and the owner opted for euthanasia. To the author's knowledge this case report is the first to report a wandering implant after implantation of a CsA device. Since this complication might have been caused by exposing the complete uvea during surgery, there should be caution during preparing of the scleral flap.
\end{abstract}

Keywords: equine / cyclosporine / implant / wandering / uveitis

\section{Komplikation nach Einsatz eines suoprachoroidalen Cyclosporin-Implantats bei einem Pferd - ein wanderndes Implantat}

Eine 19-jährige Holländer Warmblutstute wurde zur Untersuchung eines akuten Korneaödems des rechten Auges eingewiesen. Die ophthalmologische Untersuchung ergab ein vertikales Band ödematisierter Kornea, Ablagerungen auf deren Endothel sowie Miosis. Der Augeninnendruck betrug $15 \mathrm{~mm} \mathrm{Hg}$ im Vergleich zu $19 \mathrm{~mm} \mathrm{HG}$ am linken Auge. Sonographisch zeigte sich weder Glaskörperinfiltrat noch Netzhautablösung. Die vorläufige Diagnose war Uveitis anterior. Das Pferd reagierte zunächste gut auf die medikamentelle Behandlung mit Dexamethason und Atropin. Vier Wochen später erlitt es nach Absetzen der Therapie jedoch ein Rezidiv, worauf ein Cyclosporin A (CsA) Implantat suprochoroidal eingestezt wurde. Der Eingriff verlief komplikationslos, postoperativ zeigte das Pferd jedoch schwere Uveitis mit Blephaorspasmus, Tränenfluss, Ödem, Miosis und ausgeprägter fibrinöser Exsudation in die vordere Augenkammer. Das Pferd antwortete wiederum gut auf die medikamentelle Behandlung. Ungefähr zwei Monate postopertaiv war das CsA-Implantat in der vorderen Augenkammer sichtbar, wobei es nicht mit der Kornea verklebt war. Über drei Monate zeigte das Pferd keinen Blepharospasmus, wohl aber Episoden leichten Korneaödems, die nach Gabe von Decamethason für gewöhnlich schnell abklangen. Vier Monate postoperativ erlitt das Pferd wieder eine schweres Korneaödem, worauf sich der Besitzer zur Euthanasie entschloss. Nach Kenntnis der Autoren ist dies der erste Bericht über ein wanderndes CsA-Implantet. Möglicherweise wurde diese Kompliaktion durch das vollständige Freilegen der Uvea während des Eingriffs verursacht, weshalb der Skleralflap vorsichtig präpariert werden sollte.

Schlüsselwörter: Pferd / Cyclosporin / Implantat / wandernd / Uveitis / Ophthalmologie / Chirurgie

\section{Introduction}

Suprachoroidal Cyclosporine-releasing ( $\mathrm{Cs} A)$ devices are used in horses with equine recurrent uveitis (ERU). The implant allows constant release of Cyclosporine A and is placed in the suprachoroidal space directly adjacent to the ciliary body (Gilger and Deeg 2011, Gilger et al. 2006). Postoperative complications described are mild conjunctival hyperemia at the surgical site, development of superficial corneal ulcers, glaucoma, mild progression of cataract and blindness (Gilger et al. 2006). The most common complications leading to vision loss are persistent uveitis episodes, glaucoma, mature cataracts and retinal detachment (Gilger and Deeg 2011, Gilger et al. 2010).

To the authors' knowledge, this is the first case report describing the complication of a wandering implant after implantation of a Suprachoroidal CsA device in a horse (Gilger et al. 2010, Bansal et al. 2012).

\section{Case History}

A 19-year-old Dutch Warmblood mare presented to Utrecht University, Department of Equine Sciences, for the evaluation of acute corneal edema of the right eye (OD). The horse initially showed swelling of the eyelids and conjunctivitis, starting two weeks before in February 2012, and was treated with corticosteroid ointment. There was improvement of the swelling of the eyelids but since one week corneal edema occurred and the horse was referred. The horse did not have any history of eye disease. The horse had a body condition score of 7 out of 9 and had no other clinical signs of disease (Henneke et al. 1983).

\section{Initial ophthalmic examination and treatment}

Upon presentation ophthalmic examination revealed a positive menace response. There was no blepharospasm. The pupil 
was miotic. There was no direct pupillary light reflex but the consensual pupillary light reflex was intact. The anterior chamber was clear. There was no cataract of the lens however no mydriatic was used to dilate the pupil and examine the complete lens. No vitreal infiltrate was visible, although the vitreous had a slightly yellow coloration. There was a vertical band of corneal edema, denser ventrally, without vascularization. With loupe magnification and with biomicroscopy, keratic precipitates were visible on the endothelium in the area of the cornea that showed the most edema. Fluorescein stainingl of the cornea was negative.

Biomicroscopic examination (SL-15 Portable Slit Lamp, Kowa, Japan) of the remainder of the anterior segment was within normal limits. Inspection of the vitreous and fundus by means of direct ophthalmoscopy was within normal limits. The intraocular pressure obtained using tonometry (Tonovet $^{\circledR}$, ICare Finland Oy, Helsinki, Finland) was $15 \mathrm{mmHg}$ in the affected eye, compared to $19 \mathrm{mmHg}$ in the contralateral eye (reference value $22.1 \pm 5.9 \mathrm{~mm} \mathrm{Hg}$ ) (Knollinger et al. 2005).

Ultrasound examination showed no vitreal infiltrate and no retinal inflammation or detachment (Fig. 1). Complete ophthalmic and ultrasound examination of the contralateral eye (OS) was within normal limits. On the basis of the clinical signs and ophthalmic examination a presumptive diagnosis of (nonspecific) anterior uveitis was made.

The horse was treated with atropine $(5 \mathrm{mg} / \mathrm{ml}$, atropine sulfate $)^{2}$ and dexamethasone $(1 \mathrm{mg} / \mathrm{ml}$, Dexamethason Ratiopharm $)^{3}$ eye drops starting with six times daily and meloxicam (Metacam $\left.{ }^{\circledR}, 15 \mathrm{mg} / \mathrm{ml}\right)^{4}$ orally once daily and reacted well to treatment.

There was a relapse early March after discontinuation of dexamethasone. Ophthalmic examination produced the same findings except for the progressive corneal edema of the complete cornea and slight blepharospasm. The horse reacted well to the same medication. The owners opted for surgery, although the horse did not show the classical signs of ERU.

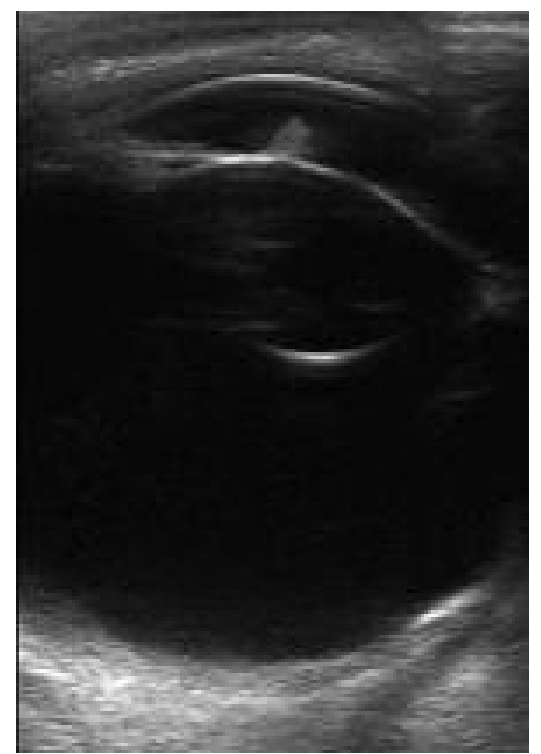

Fig. 1 Ultrasound pre-operatively (OD), showing a miotic pupil, no vitreal infiltrate or retinal inflammation or detachment.

\section{Surgical management}

The horse was placed under general anesthesia. Surgical preparation and draping of the surgical site was performed. Two stay sutures were placed in the dorsolateral conjunctiva and sclera to advance the eye ventrally to expose the dorsal sclera. A $1 \mathrm{~cm}$ conjunctival incision was made in the dorsolateral bulbar conjunctiva. A $7 \mathrm{~mm}$-wide scleral flap was prepared approximately one centimeter posterior to the limbus, exposing the black uvea over the whole area of the flap. The CsA-containing device ${ }^{5}$ was placed into the incision, in full contact with the uvea (Gilger et al. 2006). The scleral flap was closed over the implant using 5-0 polyglactin 910 suture material (Coated Vicryl*Plus Antibacterial) ${ }^{6}$ in a simple-interrupted pattern. The conjunctival incision was closed with 5-0 polyglactin 910 suture material in a simple-continuous pattern. The stay sutures were removed at the end of the surgery (Gilger and Deeg 2011). There was no leakage of vitreal fluid noticed during the complete surgery.

\section{Outcome/Follow-up}

Post-operatively medication included meloxicam for 16 days, topical antibiotics (Fucithalmic $\left.{ }^{\circledR}\right)^{7}$ and atropine ${ }^{2}$.

The first postoperative days were uneventful, but two days after surgery (21 March) the horse had severe recurrence of inflammation (ERU), more severe than before. Ophthalmic examination showed blepharospasm, lacrimation, edema of the complete cornea, a web of fibrin in the anterior chamber and a miotic pupil. On ultrasound the anterior chamber contained echogenic material and adhesions of the granula iridica with the endothelium were suspected. The vitreous was still clear (Fig. 2). Fluorescein staining of the cornea was negative. Dexamethasone was added to topical treatment and frequency of administration of atropine was increased. After a few days of intensive treatment the eye finally responded. There was less blepharospasm and the pupil widened. Examination still showed an extensive web of fibrin in the anterior chamber. At discharge the horse was comfortable, the pupil in mydriasis and the web of fibrin had reduced in size. The horse was discharged with a plan for treatment with diminished frequency.

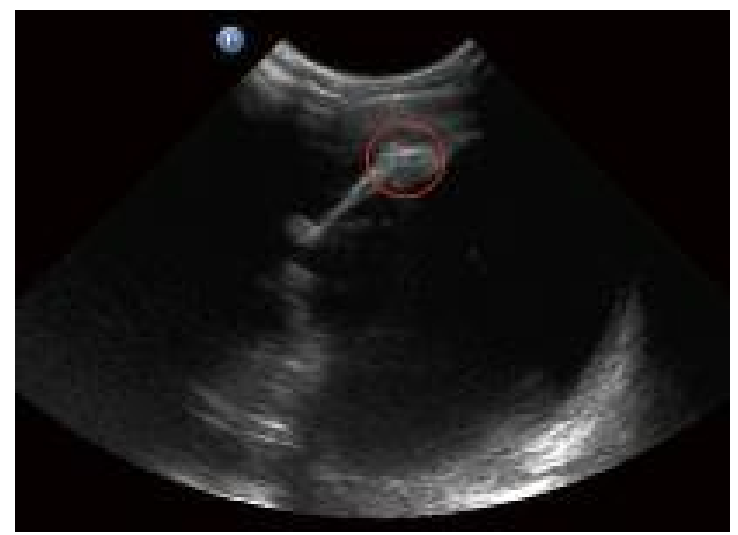

Fig. 2 Ultrasound (OD) 2 days postoperatively, showing a miotic pupil and echogenic material in the anterior chamber. Note the severe corneal edema. In retrospect, dorsally in the anterior chamber, the $\mathrm{CsA}$ device might be visible (red circle; comparison with Figure 5). 
Check-up two weeks later showed that the eye had improved, but there was still a small fibrin deposit in the anterior chamber. During the following months the horse was treated with dexamethasone eye drops once daily by the owner (because the owner did not feel comfortable with stopping dexamethasone entirely).

On the 5th of June the owner phoned that she thought she could see the CsA device. The horse was admitted again and ophthalmic examination undeniably showed the device ventrally in the anterior chamber (Fig. 3). The CsA device was not attached to the cornea, because after every brisk eye movement the implant moved a little bit. The horse did not show any discomfort. The cornea was clear except for a significant dorsal limbal opacity with vascularisation. The anterior chamber still contained some residual web of fibrin attached to the CsA device and there was a small hemorrhage on the dorsonasal corpora nigra. No other abnormalities were seen during ophthalmic examination.

For three months the horse showed no blepharospasm or other signs of ocular discomfort but had episodes of slight corneal edema. This usually cleared quickly after treatment with dexamethasone.

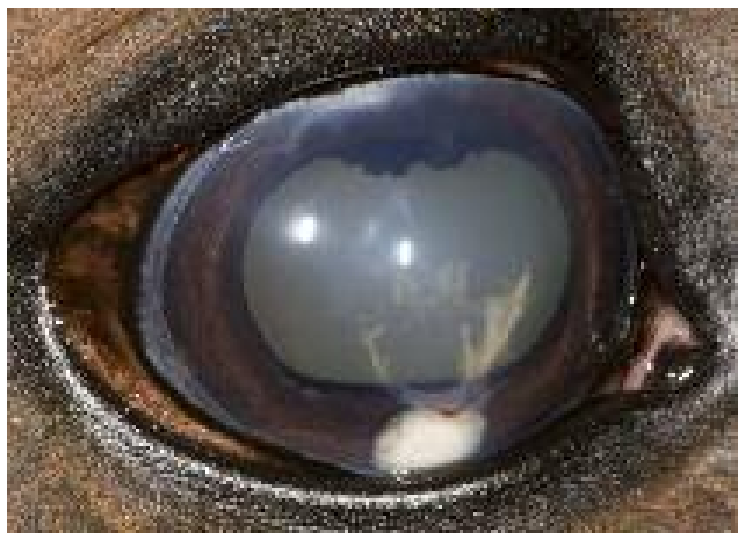

Fig. 3 Right eye (OD) showing the $C_{s} A$ device in the anterior eye chamber. Note the dorsal limbal opacity with vascularisation, the residual web of fibrin in the anterior chamber attached to the CsA device and the small hemorrhage on the dorsonasal corpora nigra.

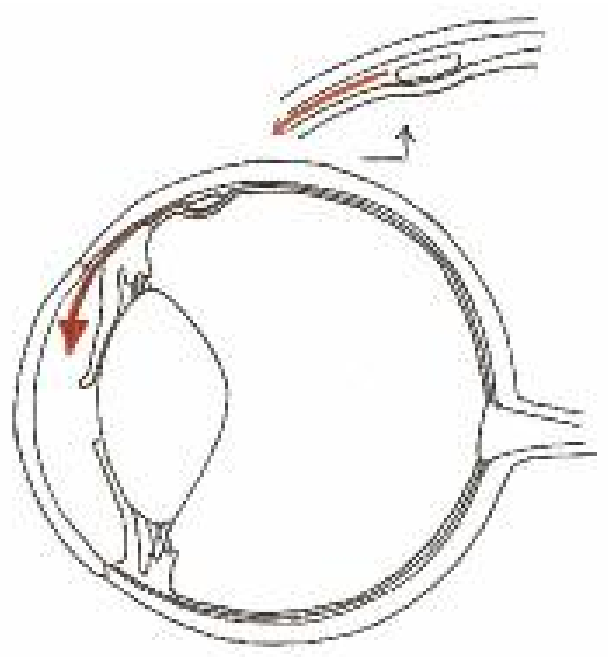

Fig. 4 Drawing of the suspected migration tract of the $C_{s} A$ device into the anterior eye chamber.
Four months after surgery, the horse had an episode with severe corneal edema and the owner opted for euthanasia. Unfortunately, the owner gave no consent for necropsy.

\section{Discussion}

Horses with chronic documented ERU that have little or no active inflammation but are experiencing frequent recurrences or early relapse of active ERU after stopping medications are ideal candidates for a CsA device (Gilger et al. 2006, Gilger and Deeg 2011). The horse in this case report did not show the classical signs of ERU but a presumptive diagnosis of (nonspecific) anterior uveitis was made, due to the clinical signs and ophthalmic examination of the eye showing a miotic pupil and keratic precipitates on the corneal endothelium and good reaction to medication. Histopathologic diagnosis of similar cases showed inflammation of the uvea and the keratic precipitates in these cases consisted of inflammatory cells and fibrosis. Unfortunately the horse was not euthanized in our clinic and therefore, no histopathologic examination of the eye was done and the presumptive diagnosis was not confirmed.

The implantation of the CsA device was performed routinely as previously described by Gilger, with the only difference that the scleral flap completely exposed the uveal tract instead of having the black uvea just visible through the sclera (Gilger and Deeg 2006). This was because in our experience, in eyes that were enucleated when a CsA device gave no improvement, a layer of connective tissue had formed between the implant and the uvea. Macroscopic examination showed that the scleral tissue underlying the implant was as thick as the overlying scleral tissue (scleral flap). We suspected in these cases that there was no significant drug delivery to the uveal circulation of the CsA device, although the intravitreal concentrations of $\mathrm{Cs} A$ were not measured in these cases. Owners do not often opt for placement of a second CsA device in our clinic. For this reason we decided to make a slightly deeper incision of the sclera tissue so the CsA device was completely in contact with the uvea.

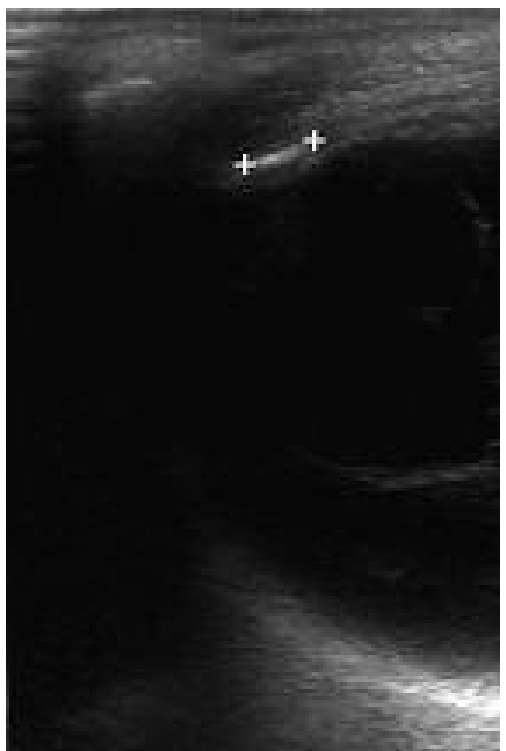

Fig. 5 Ultrasound of a horse with ERU a week after placing a CsA device. The CsA device is visible suprachoroidal dorsally. 
We suspect that the CsA device has slid between the sclera tissue and the uveal tract until it moved into the anterior chamber, causing the so called wandering implant (Bansal et al. 2012, Vela et al. 2012) (Fig. 4). This also explains the described dorsal limbal opacity with vascularisation and the small hemorrhage on the dorsonasal corpora nigra, seen at ophthalmic examination postoperatively (Fig. 3). If the device eroded vertically through the uvea in the location it was implanted, bleeding and a more vitreal location of the device was expected.

In retrospect we cannot say for sure whether the CsA device moved to the anterior chamber in the first days after surgery, when the horse had a recurrence of ERU (and was hidden in the fibrin) or later. It is described that $25 \%$ of the horses have a mild flare-up after surgery, especially after discontinuation of the NSAIDs (Gilger and Deeg 2011). This horse had a more severe episode of ERU postoperatively than we have seen in other horses after CsA device implantation. This could be taken as an indication that the CsA device moved to the anterior chamber in the first days after surgery. The ultrasound postoperatively did not visualize the CsA device, but only echogenic material in the anterior chamber. If we would have had any suspicion of a wandering implant postoperatively, a more thorough search might have been done by ultrasound (Fig. 3). Ultrasound to visualize the CsA device is a possibility if there is any doubt about correct placement of the device (Fig. 5).

In humans wandering implants are described in patients who received intravitreal injection with $O$ zurdex ${ }^{\circledR}$ implants in eyes with post-lensectomy-vitrectomy aphakia. In these cases the implant migrated into the anterior chamber and wandered between the anterior chamber and vitreous cavity with changing postures of the patients. Further follow-up in these cases revealed a deleterious effect on the corneal endothelium (like folding of the descemet's membrane) (Bansal et al. 2012, Vela et al 2012). The horse in our case report had episodes of slight corneal edema after migration of the implant to the anterior chamber. Due to the effects on the corneal endothelium surgical removal of the device or enucleation of the eye would be indicated. The owner in this case declined further surgery for the horse and opted for euthanasia when the horse had an episode with severe corneal edema.

To our knowledge this case report is the first to report a wandering implant after implantation of a CsA device. Since this complication might have been caused by exposing the complete uvea there should be caution during preparing of the scleral flap.

\section{Manufacturers' addresses}

1 Haags-Streit International, Köniz, Switzerland

2 ASTfarma, the Netherlands

3 Ratiopharm, the Netherlands

4 Boehringer Ingelheim Vetmedica GmbH, Germany

5 North Carolina State University, Veterinary Health Complex Pharmacy, USA

6 Ethicon Inc, Somerville, New Jersey

7 Dechra Veterinary Products, Denmark

\section{References}

Bansal R., Bansal P., Kulkarni P., Gupta V., Sharma A. and Gupta A. (2012) Wandering Ozurdex ${ }^{\circledR}$ implant. J. Ophthalmic. Inflamm. Infect. 2, 1-5

Gilger B. C., Salmon J. H., Wilkie D. A., Cruysberg L. P. J., Jonghyeon K., Hayat M., Hyuncheol K., Kim S., Yuan P., Lee S. S., Harrington S. M., Murray P. R., Edelhauser H. F., Csaky K. G. and Robinson M. R. (2006) A novel bioerodible deep scleral lamellar cyclosporine implant for uveitis. Invest. Ophthalmol. Vis. Sci. 47, 25962605

Gilger B. C., Wilkie D. A., Clode A. B., McMullen Jr. R. J., Utter M. E., Komaromy A. M., Brooks D. E. and Salmon J. H. (2010) Longterm outcome after implantation of a suprachoroidal cyclosporine drug delivery device in horses with recurrent uveitis. Vet. Ophthalmol. 13, 294-300

Gilger B. C. and Deeg C. (2011) Equine Recurrent Uveitis. In: Equine Ophthalmology, 2nd edn., Ed: B.C. Gilger, Elsevier Saunders, Maryland Heights, MO. pp 317-349

Henneke D. R., Potter G. D., Krieder J. L. and Yeates B. F. (1983) Relationship between condition score, physical measurements and body fat percentage in mares. Equine Vet. J. 15, 371-372

Knollinger A. M., La Croix N. C., Barrett P. M. and Miller P. E. (2005) Evaluation of a rebound tonometer for measuring intraocular pressure in dogs and horses. J. Am. Vet. Med. Assoc. 227, $244-$ 248

Vela J. I., Crespi J. and Andreu D. (2012) Repositioning of dexamethasone intravitreal implant (Ozurdex) migrated into the anterior chamber. Int. Ophthalmol. 32, 583-584

Hanneke Hermans DVM

Department of Equine Sciences

Faculty of Veterinary Medicine

Utrecht University

Utrecht

The Netherlands

h.hermans@uu.nl 